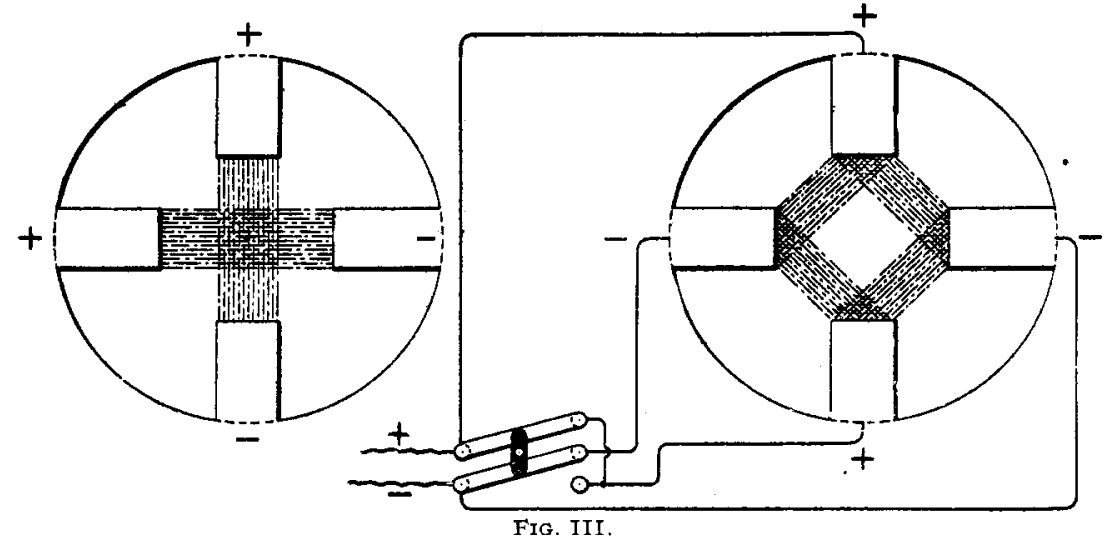

ners between the electrodes. We use the 2-phase current, with one phase put on one side and the other phase on the other. Now, if pillars form in the corners, and the conductivity of the furnace is not just right, we sometimes change over and run the current to adjacent electrodes to burn out the pillars. This change is shown in Fig. III.

The provision for the sulphur is, I believe, one of the most important features of the furnace structure. never yet been able to put enough current into one of these furnaces to enable us to keep all of these perfectly full. I am looking forward in a few weeks to being able to do that, and I anticipate that I shall be able to produce from 25,000-30,000 lbs. of carbon bisulphide in one of these furnaces in twenty-four hours. We have already produced I6,000 lbs. in twenty-four hours, as it is, but with sufficient power to go into the same furnace, it will practically double the output.

PENN YAN, NEW YORK.

\section{THE OCCURRENCE OF EFFLORESCENCE ON LAVA BRICKS.}

By William McGeorge.

Received March 20, 1912.

It is a common occurrence to see brick walls partially covered with a white film generally most abundant under the eaves and window-sills but more or less scattered over the whole building. This film is com-

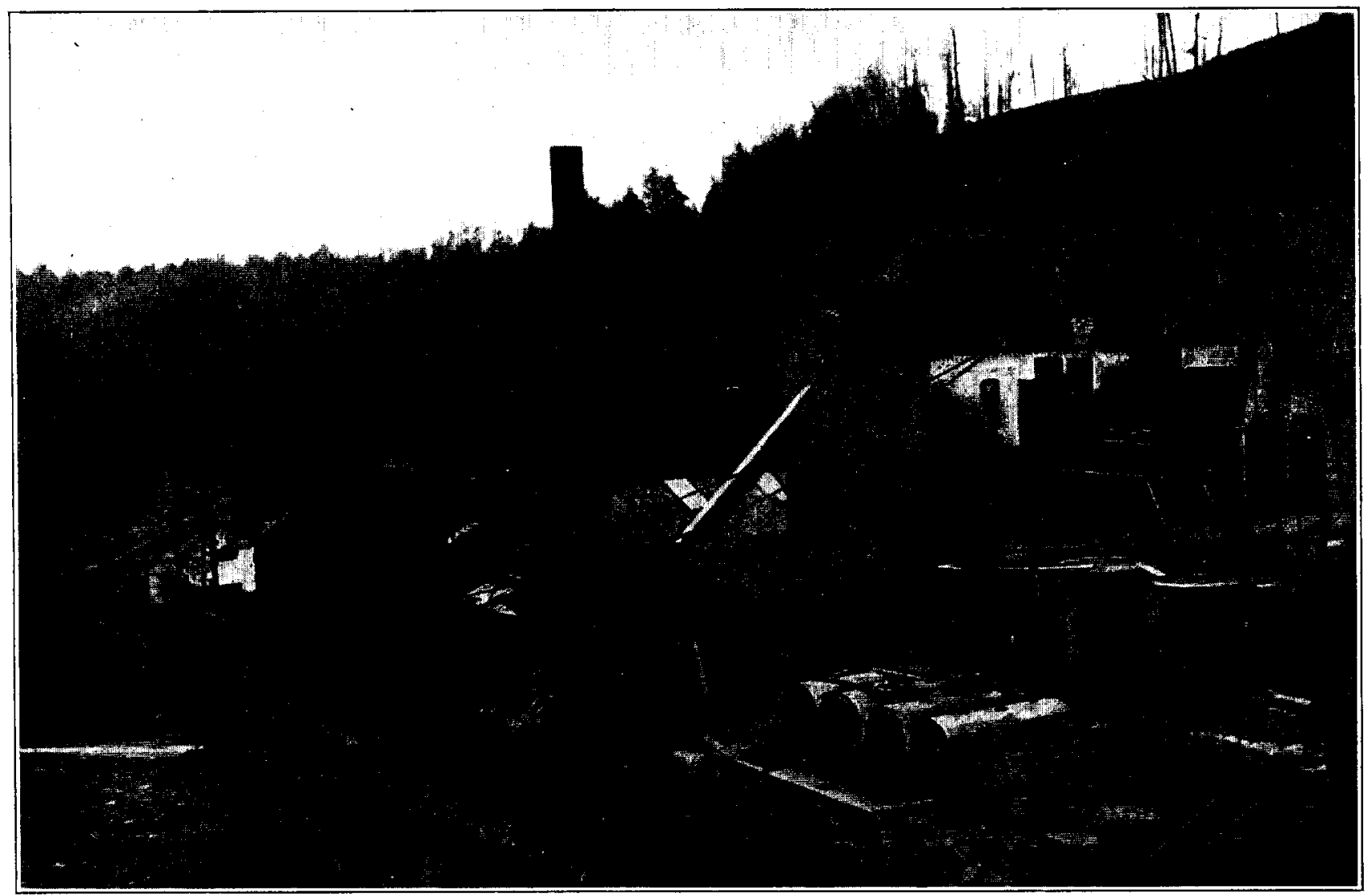

Carbon Bisulphide Plant, Penn yan, Niew York.

We are able to lag the furnace from the insicle instead of outside, and we lag it with the very materials used in the production of the carbon bisulphide.

Now the more perfectly we can carry this out, and the more completely full all of these channels can be kept with sulphur, the greater the economy will be in the production of the goods. The real fact is I have posed of soluble salts which, being washed from the interior, on appearance at the surface and subsequent evaporation of the water are deposited as a film. In most cases it is composed of sulphates of calcium, magnesium, potassium or sodium. The carbonates of calcium and magnesium are considered too insoluble to appear and those of sodium and potassium too 
soluble to remain on the surface of the brick. This film may be attributed to several causes, a few of which are as follows: (I) presence of soluble salts in the materials used, (2) soluble salts formed directly or indirectly through the action of the vapors in the drying kiln, (3) soluble salts formed through the action of the mortar after the bricks have been placed in the wall.

Undoubtedly most of the cases of efflorescence may be traced to cause ( $I$ ); namely, the presence of soluble matter in the material used. In our case it was noticed that the appearance varied with the degree of porosity or compactness of the finished brick, the more porous brick being covered with a heavy film soon after being placed in the yard. The more compact ones being less easily penetrated by the rains kept their natural appearance longer or did not have so heavy a film.

The Honolulu Lava Brick Company is making brick from dark gray basaltic lava rock such as is used for building purposes in the islands. This rock exists in large quantities on this island (Oahu) and contains a comparatively high percentage of water soluble matter. Their process is essentially as follows: the rock is ground in a mill to a fine powder, to which after the addition of a small per cent. of lime, cement or both, according to formula, enough water is added to dampen the mixture. The whole is then run into a press and pressed into brick. They are then dried in a manner best suited for the setting of the lime or cement. The resulting product has shown excellent physical tests and is a good grade of building brick of gray color. It has been noticed, however, from the beginning, that some of the bricks, soon after being wetted by the rain, became covered with a heavy white efflorescence. At first it makes its appearance in the form of needle-like crystals shooting out from the pores of the brick. Later as the quantity increases the deposit becomes heavy and can be scraped from the surface in large amounts.

Without ascertaining the composition of this film the company tried several methods of eradicating it, which had been recommended by different people. Two of these were addition of barytes which had little or no effect, and the painting of the surface with oil, which in this case did not even have a temporary retaining effect.

Upon making an analysis of this film it was found to be composed essentially of a mixture of sodium and potassium carbonates. The following is a complete analysis:

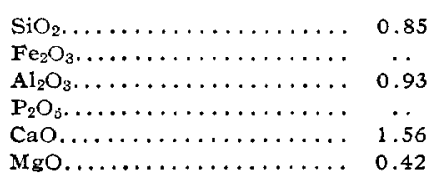

$\begin{array}{lr}\mathrm{H}_{2} \mathrm{O} & 24.32 \\ \mathrm{Na} a_{2} \mathrm{O} & 29.81 \\ \mathrm{~K}_{2} \mathrm{O} & 10.14 \\ \mathrm{SO}_{3} & 0.32 \\ \mathrm{Cl} & 0.20 \\ \mathrm{CO}_{2} & 31.39\end{array}$

It may be seen at a glance that it is composed of extremely soluble constituents. In fact, it may be dissolved by placing in the palm of the hand and rubbing with the finger. On the other hand it does not agree very closely with the composition of the soluble matter existing in the rock.

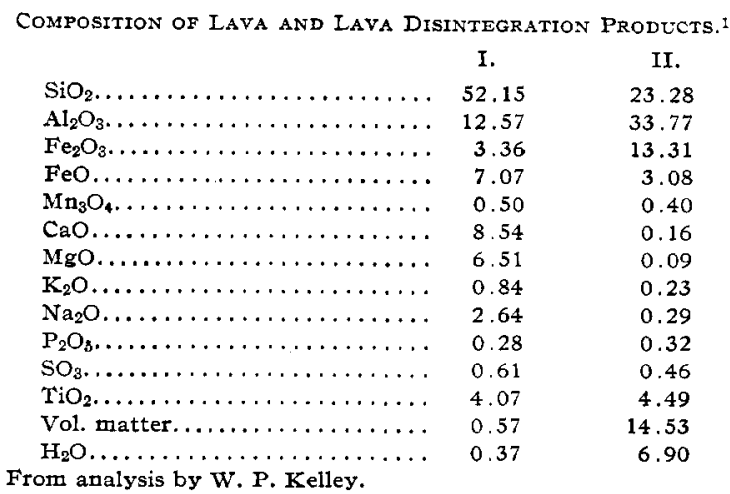

The above table shows the effects of weathering and disintegration upon lava rock and incidentally the soluble and insoluble constituents. Column $I$ is an analysis of lava rock and II is its disintegration product taken out of the gulch at the edge of I where the rock was badly disintegrated and most of the soluble matter washed out into the soil. The samples were taken very close to each other and were originally of the same composition. Hence these analyses show conclusively that the major part of the soluble matter is calcium, magnesium and silica, while sodium and potassium are of only secondary importance. It may be stated at this point that the lava rock mass contains little or no carbonate, but a large percentage of these lavas have a vesicular structure and these vesicles or holes are in many cases coated with a film of salts, varying in composition. Some of these are composed of carbonates. While the above table shows the relative solubility of the various ingredients it presents no data which would hinder one from concluding that the sodium and potassium were dissolved out more quickly during the weathering stages than the other ingredients, even though a larger relative percentage of them remains in the residue. If this were true it would account for the small percentage of calcium and magnesium in the film. Accordingly, a set of leaching experiments were run to ascertain if the above were true and to test out the possibility of leaching the ground rock before pressing, thereby removing the soluble matter as far as possible from the material. The results of leaching the ground rock are shown in the following tables, and proved entirely impracticable. Although the soluble matter of which the film is composed decreases, it does so only to a slight extent, while the calcium and magnesium are leached out very rapidly as sulphates.

\begin{tabular}{|c|c|c|c|c|}
\hline Solvbili & $\begin{array}{l}\text { Y OF CR } \\
\text { I. }\end{array}$ & $\begin{array}{l}\text { ED LAVA } \\
\text { II. }\end{array}$ & $\begin{array}{l}\text { Hot } \mathrm{H} \\
\text { III. }\end{array}$ & IV. \\
\hline $\mathrm{SiO}_{2} \ldots$ & 0.97 & 17.30 & 16.05 & 16.17 \\
\hline $\mathrm{CaO} \ldots \ldots \ldots \ldots$ & 13.75 & 0.26 & 0.28 & 0.27 \\
\hline $\mathrm{SO}_{3} \ldots \ldots \ldots \ldots \ldots$ & 36.48 & 5.04 & 3.50 & 2.28 \\
\hline Mgo $\ldots \ldots \ldots \ldots \ldots$ & 3.98 & 0.18 & 0.56 & 0.21 \\
\hline $\mathrm{Na}_{2} \mathrm{O}, \ldots \ldots \ldots$ & 32.10 & 21.66 & 34.78 & 16.10 \\
\hline $\mathrm{K}_{2} \mathrm{O} \ldots \ldots \ldots \ldots$ & 1.86 & 1.54 & 5.46 & 4.65 \\
\hline Res. in $100 \mathrm{cc} . .$. & 0.9851 & 0.9516 & 0.8288 & 0.7442 \\
\hline
\end{tabular}

'The above table shows the results obtained by leaching the ground rock with hot water for eleven 
days. Leachings were made by allowing the ground rock to remain in an iron tank containing hot water. After one hour the leachings were drawn off and the partial analysis made on this solution is shown in column I. Fresh hot water was then added and allowed to remain twenty four hours and this repeated for eleven days. Column II represents the partial analysis of the solution obtained after one day in contact with the ground rock following the one-hour extraction, column III, that on the fourth day and IV, the eleventh day. Constituents are given in percentages in solids obtained from leaching waters and grams of solids per roo cc. of solution are shown at the bottom. The first leaching was neutral to litmus and all the rest were decidedly alkaline.

Leaching with cold water was also tried but the experiment was stopped at the end of the third day. A glance at the following table will show that the action of the hot and the cold water was about the same except that the latter was much slower.

\begin{tabular}{|c|c|c|c|}
\hline SOLCBILITY OF & $\begin{array}{c}\text { Crushed I } \\
1 \mathrm{hr} .\end{array}$ & $\begin{array}{l}\text { IN Cold } \\
2 \text { days. }\end{array}$ & $\begin{array}{l}\text { WATER. } \\
\qquad 3 \text { days. }\end{array}$ \\
\hline $\mathrm{SiO}_{2}, \ldots$ & 1.44 & 13.28 & 15.30 \\
\hline $\mathrm{CaO} \ldots$ & 20.92 & 6.53 & 5.16 \\
\hline $\mathrm{SO}_{3} \ldots$ & 28.26 & 11.08 & 10.68 \\
\hline $\mathrm{MgO}$. & 0.94 & 6.32 & 6.04 \\
\hline $\mathrm{Na}_{2} \mathrm{O}$ & 14.58 & 21.76 & 45.52 \\
\hline $\mathrm{K}_{2} \mathrm{O} \ldots$ & 1.78 & 5.56 & 6.06 \\
\hline Res. in $100 \mathrm{cc} \ldots \ldots$ & 0.4637 & 0.0594 & 0.06 \\
\hline
\end{tabular}

This table also shows percentages in the solid matter in the leaching waters and grams of solid matter in roo cc. Bricks made from the leached rock also developed efflorescence. The major part of the difference between the sum of the constituents recorded in both of the above tables and roo per cent. is made up of $\mathrm{CO}_{2}$ and water of crystallization. In the analyses of the extracts, the water and carbon dioxide varied greatly and were not considered to be of sufficient value to warrant their determination.

In addition to these leaching experiments a number of finished bricks were submerged in water to ascertain if a sort of osmosis could be set up within the brick by which a large percentage of the saline matter would be retained in the interior of the brick. They were submerged for various periods and it was found that it gave only temporary benefit.

Barium carbonate and chloride have been used as a means of removing soluble sodium and potassium compounds, their action being to replace the alkalis and form harmless by-products, the alkali compounds being washed out. However, this method has been used only in the wet process and in cases where the percentage of sodium is much less than ours. As stated above when used in our case it had no effect and altered very little the indefiniteness of the time it would take the various weathering agents to remove the salts by the washing of the rain, evaporation and drawing to the surface of more saline matter.

Upon further investigation it was noticed that those bricks to which lime had been added invariably gave a thick efflorescence, increasing with an increase in the percentage of lime added. Then this same rock has been used as a building stone in its natural state and while it is quite porous has rarely shown any of the above efflorescence when used as such. From these facts it appears that the addition of lime is the cause, at least in part, of the trouble. On the other hand it is absolutely necessary to add some binding material to hold the brick together after it comes from the press. While a brick may be made simply by dampening the ground rock and pressing, the corners chip easily upon handling.

Sirice there seemed to be no chemical means of complete removal or precipitation of the saline matter and addition of lime was partly the cause of the appearance of the film, through its alkaline action on the sodium and potassium and subsequent conversion of these into carbonates, the problem narrowed down to an elimination of the lime, if possible, and the addition of a binding agent which would give a more compact brick as well as one which might have some osmotic properties.

Potassium and sodium are known to occur in basaltic lava in the form of complex silicates. From this fact it is apparent that these silicates are acted upon by the lime, since the bricks after being pressed are run into drying kilns and heated under pressure with steam. The lime, under pressure and at the high temperature of the kiln, reacts with the sodium and potassium in the complex silicates and forms caustic soda and potash as by-products which upon appearance at the surface are converted by the carbon dioxide of the air into carbonates and bicarbonates of the alkalis. If this were true then an elimination of the use of lime as a binding agent should eliminate the trouble. This was done and a small per cent. of cement was used in its stead and the method of drying altered. In this way a more compact brick was obtained and at present writing the alteration is producing decidedly better results.

Thanks are due Mr. W. P. Kelley for valuable suggestions; also for the analyses showing effects of disintegration on lava rock, these analyses being taken from investigations made by him on lava disintegration.

Contribution No. 4, Federal Experiment Station, HONOLULU, HAWAII.

\section{ENAMELS FOR SHEET STEEL. ${ }^{2}$}

BY ROBERT D. LANDRUM.

Received April 4, 1912.

Enamels for sheet steel are boro-silicates of sodium, potassium, calcium and aluminum and are, in every sense of the word, glasses. Such enamels are so compounded that they form a homogeneous, glossy coating on the surface of the sheet steel utensil, which will not be corroded by the acids or alkalies used in cooking and which will resist punishment both by impact and by rapid changes of temperature.

Although an enamel is a glass, the fact that it must adhere to steel and resist the abuse common to cooking utensils makes necessary the addition of other ingredients besides those used in manufacturing ordinary glass. In enamels, ground quartz, flint or sand supply the silica, and feldspar and clay, the alumina. Fluor-

${ }^{1}$ Delivered before the Chemists' Club of Rochester at the University of Rochester, Rochester, New York, April 1, 1912. 